\title{
XXXVI. An account of some experiments and observations on the constituent parts of certain astringent vegetables; and on their operation in tanning
}

\author{
Humphry Davy Esq.
}

To cite this article: Humphry Davy Esq. (1803) XXXVI. An account of some experiments and observations on the constituent parts of certain astringent vegetables; and on their operation in tanning , Philosophical Magazine Series 1, 17:67, 212-217, DOI: 10.1080/14786440308676402

To link to this article: http://dx.doi.org/10.1080/14786440308676402

$$
\text { 曲 Published online: } 18 \text { May } 2009 .
$$

Submit your article to this journal ए

\section{山ll Article views: 3}

Q View related articles ¿ 


\section{[ 212]}

XXXVI. An Account of somè Experiments and Ouservations on the constitnent Parts of certain astringent Vegetalles; and on their Operation in Tanning. By $\mathrm{HUM-}$ phry Davy, Esq. Professor of Chemistry in the Royal Institution.

[Continued from p. 76.$]$

\section{Experiments and Olservations on Catechu or Terra Japonica.}

T wood of a species of the mimosa , which is found abundantly in India, by decoction and subsequent evaporation.

There are two kinds of this extract; one is sent from Bombay, the other from Bengal; and they differ from each other more in their external appearance than in their chemical composition. The extract from Bombay is of an uniform texture, and of a red brown tint, its specific gravity being generally about $1 \cdot 39$. The extract from Bengal is more triable, and less consistent; its colour is like that of chocolate externally, but, when broken, its fracture presents streaks of chocolate and of red brown. Its specific gravity is about $1 \cdot 28$. Their tastes are precisely similar, being astringent, but leaving in the mouth a sensation of swectness. They do not deliquesce, or apparently change, by exposure to the air.

The discovery of the tanning powers of catechu is owing to the president of the Royal Society, who, concluding from its sensible properties that it contained tannin, furnished me, in December 1801, with a quantity for chemical examination.

In my first experiments, I found that the solutions of catcchu copiously precipitated gelatine, and speedily tanned skin ; and, in consequence, 1 began a particular investigation of their properties.

The strongest infusions and decoctions of the two different kinds of catechu do not sensibly differ in their nature, or in their composition. Their colour is deep red brown, and they communicate this tinge to paper; they slightly redden litmus paper; their taste is highly astrinrent, and they have no perceptible sinell.

The strongest infusions that I could obtain from the two Linds of catechu, at $48^{\circ}$ Fahrenheit, were of the same specilic gravity, 1.057: but, by long decoction, I procured so-

if Sce Kerr. Midical Observatiun, vol. v. R. 155 .

lutions 
lutions of $1 \cdot 102$, which gave, by evaporation, more than 1-6th of their weight of solid matter.

Five hundred grains of the strongest infusion of catechu from Bombay, furnished only 41 grains of solid matter; which, from analysis, appeared to consist of 34 grains of tamnin, or matter precipitable by gelatine, and 7 grains that were chiefly a peculiar extractive matter, the properties of which will be hereafter described. The quantity of solid matter given by the strongest infusion of the Bengal catechu was the same, and there was no sensible difference in its composition. Portions of these solid matters, when incinerated, left a residnum which seemed to be calcareous; but it was too small in quantity to be accurately examined, and it could not have amounted to more than $\frac{1}{2} \frac{1}{0}$ th of their original weights.

The strongest infusions of catechu acted upon the acids and pure alkalis in a manner analogous to the infusion of galls. With the concentrated sulphuric and muriatic acids, they gave dense light fawn-coloured precipitates. With strong nitrous acid they effervesced; and lost their power of precipitating the solutions of isinglass, and the salts of iron. The pure alkalis entered into union with their tannin, so as to prevent it from being acted upon by gelatine.

When the solutions of lime, of strontia, or of barytes, were poured into the infusions, copious precipitates, of a shade of light brown, were formed; and the residual fluid assumed a paler tint of red, and was found to have lost its power of precipitating gelatine.

After lime had been boiled for some time with a portion of the infusion, it assumed a dull red colour. The liquor that passed from it through the filter had only a faint tint of red, did not act upon gelatine, and seemed to contain only a very small portion of vegetable matter. Pure magnesia, when heated with the infusion, acted upon it in an analogous manner; the magnesia became light red, and the residual fluid had only a very slight tinge of that colour. With carbonate of magnesia, the infusion became deeper in colour, and lost its power of precipitating gelatine; though it still gave, with oxygenated sulphate of iron, a light olive precipitate.

The carbonates of potash, of soda, and of ammonia, in their concentrated solutions, produced only a slight degree of turbidness in the infusion of catechu: they communicated to them a darker colour, and deprived them of the power of acting upon gelatine; though this power was restored by the addition of an acid. 
After the mixture of the solution of carbonate of potast; and the infusions had been exposed to the atmosphere fait some hours, a brown crust was found to have formed upon its surface, and a slight precipitation had taken place.

The salts of alumine precipitated the infusions; but less copiously than they precipitate the intusion of galls. A similar effect was produced by nitrate of potash, sulphate of magnesia, prussiate of patash, and many other neutral salts.

The nitrate, or acetite, of lead, in concentrated solution, when poured into the infusion produced in it a dense light brown precipitate, which gave to the fluid a gelatinous appearance. After this effect, there was no free acid found in it ; and both the tannin and the extractive matter seemed to have been carried down in union with a portion of the metallic salt.

The solution of muriate of tin acted upan the infusion of catechu in a manner similar to that in which it acts upon the infusion of galls.

The least oxygenated sulphate of iron produced no change in the infusion. With the most oxygenated sulphate it gave a dense black precipitate, which, when diffused upon paper, appeared rather more inclined to olive than the precipitate from galls.

The infusions were procipitated by the solution of atbumen.

The precipitates by gelatine had all a pale tint of red brown, which became eeeper when they were exposed to the air. The conpound of gelatine and the tanmin of the strongest infusions of catcchu appeared, by estimation of the quantity of isinglass in the solutions used for their precipitation, to consist of about 41 parts af tamin and 59 of gelatine.

Of two pieces of calf-skin which weighed, when dry, 132 grains each, and which had been prepared for tanning, one was immersed in 'a large quantity of the infusion of catechu from Bengal, and the other in an equal portion of the infusion of that from Bombay. In less than a month they were found converted into leather. When freed from moisture, by long exposure in the sunshine, they were weighed. The first piece had gained about 34 grains, and the second piece $35 \frac{1}{2}$ grains. The leather was of a much deeper colour than that tanned with galls, and on the upper surface was red brown. It was not acted on by hot or colel water; and its apparent strength was the same as that of similar leather tanned in the usual manner. 
In examining the remainder of the infusions of catechu, in which skin had been converted into leather, I found in them much less extractive matter than I had reason to expect, from the comparative analysis of equal portions of the unaltered infusions made by solutions of gelatine. At first, I was inclined to suppose that the deficiency arose from the action of the atmosphere upon the extractive matter, by which a part of it was rendered insoluble. But, on considering that there had been very little precipitation in the process, I was led to adopt the supposition, that it had entered into union with the skin at the same time with the tannin; and this supposition was confirmed by new experiments.

Both kinds of catechu are almost wholly soluble in large quantities of water; and, to form a complete solution, about 18 ounces of water, at $52^{\circ}$, are required to 100 grains of cxtract. The residuum seldom amounts to $\frac{1}{14}$ th of the original weight of the catechu: and, in most cases, it is found to consist chiefly of calcareous and aluminous earths, and of fine sand, which, by accident or design, had probably been mixed with the primitive infusion at the time of its evaporation.

A considerable portion of both kinds of catechu is soluble in alcohol; but, after the action of aleohol upon it, a substance remains of a gelatinous appearance and a light brown colour, which is soluble in water, and is analogous in its properties to gum or mucilage.

The peculiar extractive matter in the catechu is much less soluble in water than the tanning principle; and, when a small quantity of water is used to a large quantity of catechu, the quantity of tannin taken up, as appears from the nature of the strongest infusion, is very much greater than that of the extractive matter.

The extractive matter is much more soluble in warm water than in cold water; and, when saturated solutions of catechu are made in boiling water, a considerable quantity of extractive matter, in its pure state, falls down as the liquor becomes cool.

The peculiar extractive matter of the catechu may be likewise obtained by repeatedly lixiviating the catechu, when in fine powder, till the fluids obtained cease to precipitate relatine; the resighal solid will then be found to be the substance in question.

The pure extractive matter, whether procured from the Bombay or Bengal catechu, is pale, with a faint tinge of red brown. It has no perceptible smell; its taste is slightly 
astringent; but it leaves in the mouth, for some time, is sensation of sweetness stronger than that given by the catechu itself.

Its solution in water is at first yellow brown; but it gains a tint of red by exposure to the air. Its solution in alcohol docs not materially change colour in the atmosphere; and it is of an uniform dull brown.

The extractive matter, whether solid or in solution, was not found to produce any change of colour upon vegetable blucs.

It became of a brighter colour by the action of the alkalis; but it was not precinitated from its solution in water by these bodies, nor by the alkaline earths.

The aqueous solution of it, when mixed with solutions of nitrate of alumine and of muriate of tin, became slightly turbid. tion,

To nitrate of lead it gave a dense light brown precipita-

Is was not perceptibly acted upon by solution of gelatine; but, when solution of sulphate of alumine was added to the mixture of the two fluids, a considerable quantity of solid matter, of a light brown coluur, was immediately deposited.

To the solution of oxygenated sulphate of iron it communicated a fine grass green tint; and a green precipitate was deposited, which became black by exposure to the air.

It was not precipitated by the mineral acids.

Linen, by being boiled in the strongest solution of the extractive matter, acquired a light red brown tint. The liquor became almost colourless; and, after this, produced very little change in the solution of oxygenated sulphate of iron.

Raw skin, prepared for tanning by being immersed in the strong solution, soon acquired the same kind of tint as the linen. It united itself to a part of the extractive matter; but it was not rendered by it insoluble in boiling water.

The solid extractive matter, when exposed to heat, softened, and became darker in its colour, but did not enter into fusion. At a temperature below that of ignition, it was decompounded. The volatile products of its decomposition were, carbonic acid, hydrocarbonate, and water holding in solution acetous acid and a little unaltered extractive matter. There remained a light and very porous charcoal.

In considering the manner in which the catechu is prepared, it would be reasonable to conclude that different spe-

cimens 
cimens of that substance must differ in some measure in their composition, even in their pure states; and, for the purposes of commerce, they are often adulterated to a considerable extent with sand and earthy matter*.

In attempting to estimate the composition of the purest catechu, I selected pieces from different specimens, with which I was supplied by the president, and reduced them together into powder; mixing, however, only those pieces which were from catechu of the same kind.

Two hundred grains of the powder, procured in this way from the catechu of Bombay, afforded by analysis

$\begin{array}{llll}\text { Tannin - } & - & - & 109 \mathrm{grs} \\ \text { Peculiar extractive matter } & - & - & 68 \\ \text { Mucilage - } & - & - & 13 \\ \text { Residual matter, chiefly sand and calcareous } \\ \text { earth }\end{array}$

The powder of the Bengal catechu gave, by similar methods of analysis, in 200 grains,

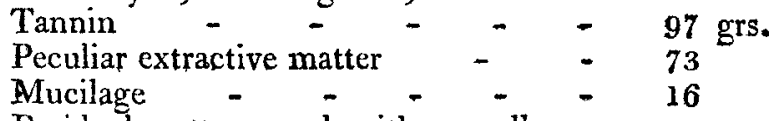

Residual matter; sand, with a small quantity of calcareous and aluminous earths, $\quad \$ 4$

In examining those parts of the catechu from Bengal which were differently coloured, I found the largest proportion of tannin in the darkest part of the substance; and most extractive matter in the lightest part. It is probable that the inequality of composition in this catechu is owing to its being evaporated and formed without much agitation; in consequence of which the constituent parts of it that are least soluble, being first precipitated, appear in some measure distinct from the more soluble parts, which assume the solid form at a later period of the process.

From the observations of Mr. Kerr $\uparrow$ it would appear that the pale catechu is that most sought after in India; and it is evidently that which contains most extractive matter. The extractive matter seems to be the substance that gives to the catechu the peculiar sweetness of taste which follows the impression of astringency; and it is probably this swectness of taste which renders it so agreeable to the Hindoos, for the purpose of chewing with the betle-nut.

[To be continued.]

* One specimen that I examined of the terra japonica of commerce, furnished, by incineration, one-fifth of sand and earthy matter; and another specimen nearly one-sixth.

† Medical Observations, fol. v. p. 155. 